\title{
An E.E.G. assessment of encephalopathy in Parkinsonism
}

\author{
JOHN LAIDLAW AND J. CATLING
}

\author{
From the Medical Research Council E.E.G. Unit, Western General Hospital, Edinburgh
}

In a review of the electroencephalographs (E.E.G.) in patients suffering from Parkinson's syndrome, England and his colleagues (England, Schwab, and Peterson, 1959) reported the association of E.E.G. slow wave abnormalities with those severe forms of the disease which showed, in addition to tremorrigidity symptoms, mental changes and akinesia. They defined akinesia as 'a reduction or loss of ability to initiate and maintain simple or complicated motor acts'. They found that patients thus severely affected were very sensitive to sedative drugs and they stated that patients with E.E.G. abnormalities and marked akinesia were bad candidates for neurolytic surgery. Hassler, Riechert, Mundinger, Umbach, and Ganglberger (1960) have reported that patients with a slow dominant frequency in their pre-operative E.E.G.s were more likely to show post-operative confusion, and the same workers stated that they considered that the E.E.G. slowing, which was produced by operation in a high proportion of their patients, did not depend on whether the stereotactic lesion was placed in the pallidum or in the ventral thalamus. There would therefore seem to be evidence to suggest that patients with 'encephalopathy' are liable to deteriorate post-operatively and that this postoperative deterioration, characterized by confusion and further slowing of the E.E.G., represents an increased encephalopathy.

The advisedly non-specific term 'encephalopathy' has been used to refer to those disorders of brain function which, when severe, are manifested by confusion or alteration of consciousness and by a severe generalized electroencephalographic abnormality with a record dominated by large, slow waves (delta dominant). Work on hepatic encephalopathy (Laidlaw and Read, 1963, 1961) has shown that patients with lesser degrees of encephalopathy may not have objective neuropsychiatric signs but may show an abnormal E.E.G., namely, a reduction in frequency of the background activity, ${ }^{1}$ a loss of

\footnotetext{
${ }^{1}$ Unless otherwise stated, E.E.G. terminology follows the recommendation of the International Federation for Electroencephalography and Clinical Neurophysiology (Electroenceph. clin. Neurophysiol., 13, 646).
}

reactivity to alerting stimuli or the interposition $\overrightarrow{\text { क् }}$ occasional delta waves. It was also found that some patients who had E.E.G.s within the wide range of normal showed a greater reduction in frequency an loss of reactivity after a small dose of morphine tham a group of controls, and these patients were said to have minimal or latent encephalopathy.

It was suggested tentatively that this particular differential E.E.G. response might have more genera application and that measuring the effect of sedative hypnotic drugs on the E.E.G. might be a useful way of demonstrating very slight or latent disorders of brain function. Further work has shown that a grAjug of epileptics given $50 \mathrm{mg}$. of intramuscular chlorpofes mazine or promazine not only showed occasionalp paroxysmal discharges not present in the rougine E.E.G.s but also, contrasted with non-epileptic $\vec{a}$ greater slowing of the background activity.

The work to be described was carried out, firsti t to see whether a group of Parkinson patients who flic not have encephalopathy sufficient to contraindie operation might nevertheless show a degree of encephalopathy, as measured by greater sensitivito to sedatives than a control group, and, secondly, to relate the pre-operative E.E.G. findings, including the response to sedatives, with the results of operation $\frac{0}{D}$

When looking in 1960 for a suitable, harmless sedative-hypnotic we unfortunately chose Thalidö mide. Although the work to be reported canno, therefore, be repeated, it is presented because other work has suggested that the results are not peculiar to the drug used and it is felt that it provides an example of a general method whereby slight ences phalopathy may be demonstrated or the degree of encephalopathy assessed.

\section{METHOD}

SUBJECTS There were 20 controls and 20 Parkinsols patients. All their E.E.G.s showed measurable back. ground rhythmic activity and were free of gross artefacto The controls were either normal volunteers or patiens? free from any disorder likely to affect the E.E.G. Th8 Parkinson patients had all been selected as suitable for 
stereotactic operations. Since an assessment was to be made of generalized E.E.G. abnormalities, Parkinson patients who showed clear localized abnormalities after operation were not included.

OPERATION The patients were operated on by three different surgeons and coagulative lesions of various sizes were placed stereotactically in the globus pallidus, the internal capsule, or the thalamus, or in a combination of these sites. Seven patients had had previous stereotactic operations. No attempt will be made to subdivide this small series according to the type or size of operation.

E.E.G. EXAMINATION The E.E.G. records were taken before and from one to one and a half hours after Thalidomide in a dose of approximately $1 \mathrm{mg} . / \mathrm{kg}$. body weight. The controls had two records, the Parkinson patients two records before and two records approximately seven days after operation. The record taken before operation and Thalidomide will be referred to as the baseline record.

The records were carried out on an Ediswan mark II machine using silver/silver chloride electrodes with time constants at 0.3 seconds, filters at 15 c.p.s., and international electrode placements. Bipolar recording was used and the channel from the postero-lateral aspect of the non-dominant hemisphere (T4-02 in a right-handed subject) was led into a B.N.I. wave form analyser. This apparatus had been modified so that the abundance (the product of amplitude and incidence) at each frequency from 2 to 12 cycles per second (c.p.s.) inclusive, instead of being written out in the conventional manner could be read directly from a microammeter. The abundance readings are in arbitrary units and the abundances at the different frequencies were measured during 15-second epochs.

The following epochs were analysed:-

$S$ Five epochs of $15 \mathrm{sec}$. at regular intervals while the subject lay for five minutes with his eyes shut.

$M$ As for $\mathrm{S}$, but with a metronome ticking at one tick per second.

Mc The subject lay with his eyes shut and was told to count silently from 1 to 20 in time with the metronome and to press a bulb, which recorded a signal on the E.E.G. record, each time he reached 20. This was repeated 15 times during five minutes and five epochs between each third signal were analysed.

The average abundance values for each type of epoch, and, for the baseline record, for all 15 epochs, were calculated. From these abundances the following parameters were worked out:-

Mean frequency This is the centre of gravity on the frequency axis of the abundances at the dominant frequency and the two frequencies on each side of it as previously described in detail (Laidlaw and Read, 1963). An epoch with the greatest abundance at 2 to 3 c.p.s. is said to be delta dominant and the mean frequency of such an epoch cannot be calculated in this way.

Delta index The delta index is the square of the sum of the abundances at 2 and 3 c.p.s. divided by the sum of the abundances at all frequencies from 2 to 12 c.p.s. inclusive. This gives a measure both of the absolute and relative abundances within the delta range (see reference to Fig. 2 under Results).

ATTENTION TEST From the signals recorded on the E.E.G. paper during the $M c$ epochs it was determined whether the subject had counted correctly in time with the metronome. A miscount of 1 or 2 either way was not treated as an error. A subject was defined as having failed the attention test if he made more than one error. A further subdivision of the degree of error would add little to the main argument of this paper but some details of the errors are given under Results.

\section{RESULTS}

PARKINSON PATIENTS CONTRASTED WITH CONTROLS Contrasting the baseline E.E.G.s, that is before drug or operation (Table I), the Parkinson patients have a significantly lower mean frequency $(P<0.001)$ and higher delta index (P=0.01-0.002) than the controls.

\section{TABLE I}

AVERAGE VALUES OF MEAN FREQUENCY AND DELTA INDEX FOR BASELINE RECORDS OF PARKINSON PATIENTS AND CONTROLS AND RESULTS OF ATTENTION TEST DURING BASELINE RECORDING

$$
\begin{array}{ll}
\begin{array}{l}
\text { No. of } \\
\text { Subjects }
\end{array} & \begin{array}{l}
\text { Average } S, M, \text { and Mc Epochs } \\
\begin{array}{l}
\text { Mean Frequency Delta Index } \\
\text { (c.p.s.) }
\end{array}
\end{array}
\end{array}
$$

\begin{tabular}{lcccc}
\hline $\begin{array}{l}\text { Controls } \\
\begin{array}{l}\text { Parkinson } \\
\text { patients }\end{array}\end{array}$ & 20 & 9.92 (s.d. 0.84) & 3.43 (s.d. 1.76) & 0 \\
& 8.83 (s.d. 0.99) & 5.34 (s.d. 2.45) & 0
\end{tabular}

Figure 1 shows the individual distribution of mean frequencies according to age for the two groups. That the control group is slightly younger than the group of patients is not considered to have affected the results since there is no relationship between age and the parameters of mean frequency or delta index. During the baseline E.E.G. no patient or control failed the attention test.

Contrasting mean frequency and delta index between comparable epochs $(S-S, M-M, M c-M c)$ before and after Thalidomide (Table II) it will be seen that both groups show an average reduction in mean frequency and an increase in delta index. In the case of the controls, although the changes are small they are significant (mean frequency $P=0.05$ 0.02 , delta index $P=0.01-0.002$ ), if one assumes a zero average change with the same standard deviation as a result of random variation. The average changes are greater in the Parkinson group and the greater response in the patients is significant (mean frequency $=\mathrm{P} 0.02-0.01$, delta index $<0.001)$. The mean frequency change cannot be calculated when one of the records is delta dominant. After Thalido- 


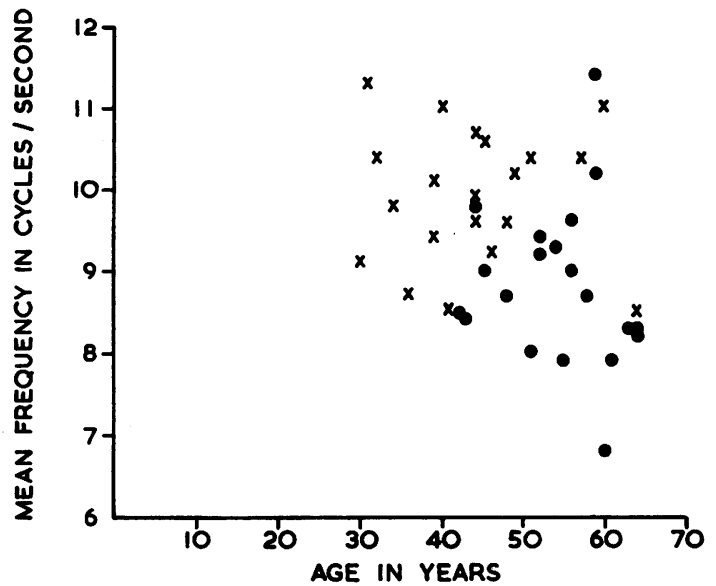

FIG. 1. The mean frequency of the baseline record in cycles per second plotted against age in years for Parkinson patients and controls. Patients $\times$ Controls

\section{TABLE II}

AVERAGE CHANGES IN MEAN FREQUENCY AND DELTA INDEX BETWEEN COMPARABLE EPOCHS BEFORE AND AFTER THALIDOMIDE AND RESULTS OF ATTENTION TEST AFTER THALIDOMIDE IN PARKINSON PATIENTS AND CONTROLS

\begin{tabular}{llccc} 
& & $\begin{array}{l}\text { No. of } \\
\text { Comparisons }\end{array}$ & $\begin{array}{l}\text { Average Change } \\
\text { after Drug } \\
S-S, M-M, \\
M c-M c,\end{array}$ & $\begin{array}{l}\text { Attention } \\
\text { Test } \\
\text { Failures } \\
\text { after } \\
\text { Drug }\end{array}$ \\
\hline Controls & $\begin{array}{l}\text { Mean } \\
\text { frequency }\end{array}$ & 59 & -0.07 (s.d. 0.25) & 1 \\
& $\begin{array}{l}\text { Delta index } \\
\text { Pean }\end{array}$ & 60 & 0.62 (s.d. 1.79) & \\
$\begin{array}{l}\text { Parkinson } \\
\text { patients }\end{array}$ & $\begin{array}{l}\text { Mequency } \\
\text { frequen } \\
\text { Delta index }\end{array}$ & 50 & -0.20 (s.d. 0.33) & 8 \\
& & 60 & 2.64 (s.d. 4.33) &
\end{tabular}

mide there were 10-delta dominant epochs in five Parkinson patients as against one such epoch in the control group. Paradoxically, if the Parkinson patients had been less affected by Thalidomide, the average figures for mean frequency change might have shown an even greater difference, since those patients who were most severely affected might not have had delta-dominant records. After operation even more delta-dominant epochs were found and so this parameter could not be used to compare the effects of Thalidomide and operation. Eight Parkinson patients failed the attention test after Thalidomide as contrasted with one control; this is significant $(P=0.05-0.01)$.

EFFECT OF OPERATION ON PARKINSON PATIENTS Table III shows the increase in the delta index above the

\section{TABLE III}

AVERAGE INCREASES IN DELTA INDEX ABOVE BASELINZ RECORD AND NUMBER OF ATTENTION TES $T$ FAILURES FOR PARKINSON PATIENTS AFTER THALIDOMIDE, AFTER OPERAQ TION, AND AFTER THALIDOMIDE AND OPERATION

\begin{tabular}{llll} 
& $\begin{array}{l}\text { After } \\
\text { Drug }\end{array}$ & $\begin{array}{l}\text { After } \\
\text { Operation }\end{array}$ & $\begin{array}{l}\text { After Drug and } \\
\text { Operation }\end{array}$ \\
\hline Increase in delta & 2.64 (s.d. 4.32) & $7 \cdot 14$ (s.d. 6.85) & 11.63 (s.d. 8.70
\end{tabular}
index

Attention test

failures

8

11

14

baseline level for the Parkinson group after Thalido mide, after operation, and when Thalidomide was్ given after operation. Each progressive increase i highly significant $(P<0.001,<0.001,0.002-0.001)^{\circ}$ There is a comparable increase in the number of patients who failed the attention test.

Of those who failed the attention test, the controt after Thalidomide had to be roused once; for the Parkinson patients after Thalidomide, five had to be: roused once and two more than once; after operation only, seven had to be roused once, one more thath once, and two were quite unable to carry out the test; and, after operation and Thalidomide, thäet had to be roused once, five more than once, and $\$$ were unable to carry out the test.

Figure 2 shows the frequency patterns before at after Thalidomide, before and after operation for patient who showed progressive E.E.G. deterioga? tion. The change in pattern pre-operatively affer Thalidomide is very similar, although less marked than that which occurred as a result of operation: The two post-operative patterns show the purpose of the method of calculating the delta index. Althougls the absolute abundances of delta waves ( 2 and $D$ c.p.s.) in the post-thalidomide pattern is rather les $\mathbb{S}^{2}$ than before, the delta index works out appreciably higher and reflects the fact that the record show much less of the relatively normal activity from 6 to 8 c.p.s. inclusive and is, therefore, more abs normal.

PREDICTION OF POST-OPERATIVE DETERIORATION Whatever may be the clinical significance, it is cleae that operation caused a number of Parkinson. patients to fail the attention test and produced of marked average increase in the delta index of the E.E.G. In order to attempt to predict pre-operatively? which patients will show these changes the individuab results are tabulated (Table IV). Column 1 lists the mean frequencies of the patients' baseline records in order of decreasing frequency. In the other columns, positive responses are marked with solid and negatives with open circles according to the following cri 


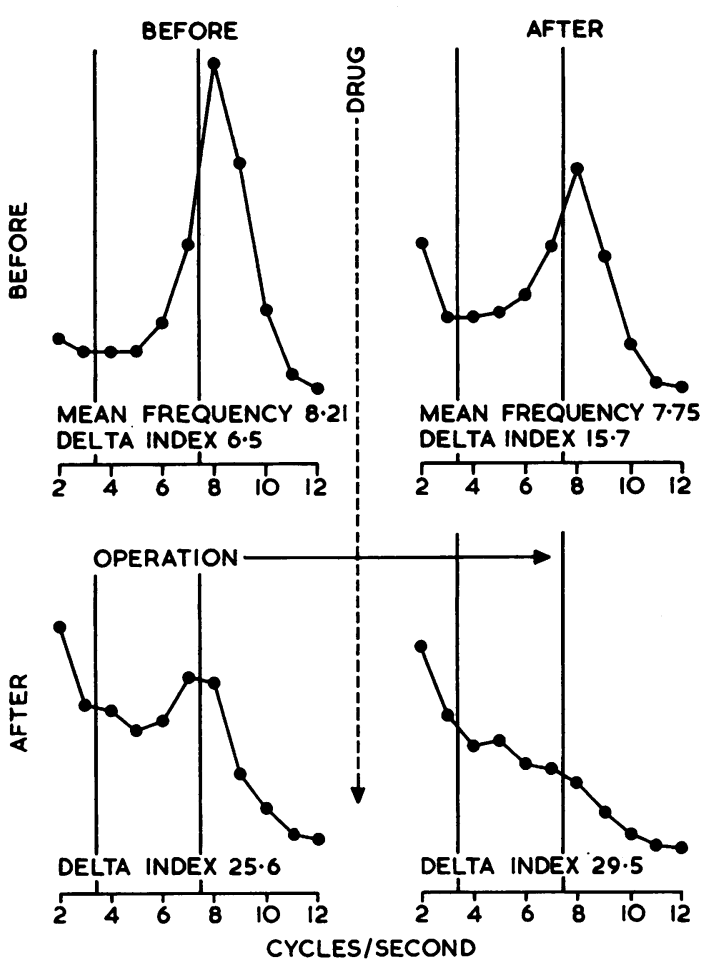

FIG. 2. Frequency patterns obtained by plotting abundances in arbitrary units against frequency in cycles per second for a Parkinson patient who showed progressive E.E.G. deterioration after Thalidomide, after operation, and when Thalidomide was given after operation.

TABLE IV

INDIVIDUAL RESULTS FOR 20 PARKINSON PATIENTS ARRANGED IN DESCENDING ORDER OF MEAN FREQUENCY OF THE BASELINE RECORD

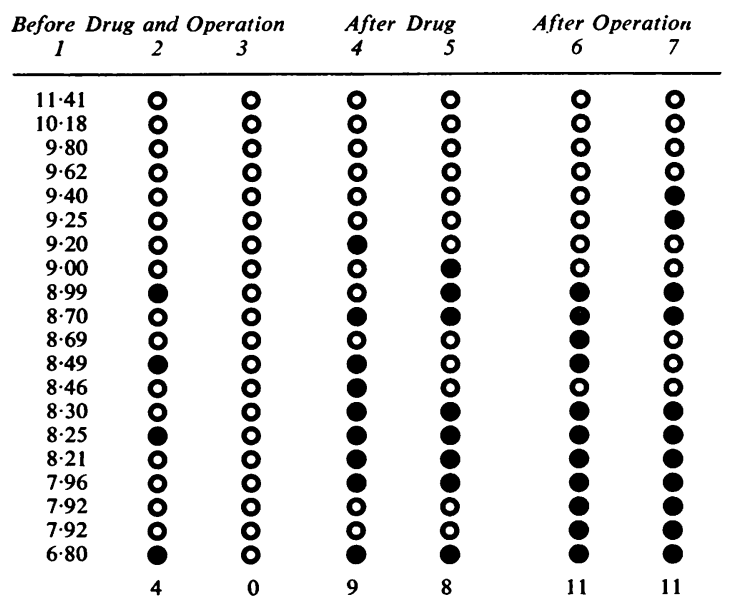

teria: 2 In the baseline record a delta index higher than that found in any control, over 6.9 units; 3 failure in the attention test during the baseline recording; 4 after Thalidomide, a greater increase in the delta index than that found in any control, more than 2.3 units; 5 failure in the attention test after Thalidomide; 6 post-operatively, an increase in delta index of more than 5 units; 7 failure in the attention test post-operatively.

From Table IV it will be seen that there are many more positive responses in patients with low baseline mean frequencies. There is a strong association between positive delta index responses and attention test failures. However, since no patient failed the test during the baseline recording, the test during this recording has no predictive value. Eleven patients showed a positive delta index response after operation; of these only four showed one for the baseline record whereas seven showed a response to Thalidomide outwith the control range. Two patients who showed a Thalidomide response did not show a postoperative one. Eleven patients failed the attention test post-operatively and of these, eight failed after Thalidomide. One control failed after Thalidomice as did one patient who did not fail post-operatively. Post-operatively, nine patients showed both a positive delta index response and failed the attention test. Of these, six could have been predicted on the basis that they showed a positive delta index response and failed the attention test after Thalidomide. Furthermore, there was no patient who showed both these responses after Thalidomide who did not also show them after operation.

\section{DISCUSSION}

Our results confirm previous reports, first, that some Parkinson patients show an excess of slow activity in their E.E.G.s, and, secondly, that there may be a slowing of the dominant rhythms and the interposition of generalized delta waves after stereotactic operations (Sirakov and Mezan, 1963; Menšiková et al., 1963; Hassler et al., 1960; England et al., 1959). In a disorder with different aetiologies and varying in severity, a wide range of E.E.G. findings might be expected. Our 20 patients were selected since they were all considered to be affected sufficiently severely to require operation, but to be well enough to be able to tolerate it. Considered as a group, they showed significantly more slow activity than the controls as measured both by the mean frequency of the background activity and the delta index of interposed and underlying slow waves (Table I). However, it may be seen that within the group there is a very wide range of mean frequency, many patients lying well within normal limits (Fig. 1) and that only four patients had 
a delta index higher than that found in the controls (Table IV).

The control group showed a small but significant reduction in mean frequency and increase in delta index after Thalidomide. The response of the Parkinson group was significantly greater than that of the controls, although individually many of the patients showed a response to the drug within the normal range. These results would suggest that some of the Parkinson patients had a mild degree of encephalopathy.

The patients were assessed seven days after operation, first, by a simple counting test which was found to require a considerable ability to sustain attention to a monotonous task and to be a sensitive index of minimal confusion, and secondly, by the calculation of the increase in the delta index of the E.E.G. This assessment showed that there was a marked increase in slow activity, and, rather surprisingly, that 11 out of 20 patients were unable to count correctly although they had been able to do so before operation. Therefore, as a group the Parkinson patients showed more encephalopathy after operation than they did before. The analysis of Table IV shows clearly that there is a strong correlation between the pre-operative E.E.G. findings and the post-operative deterioration. In particular, of nine patients who after operation both failed the attention test and showed a large increase in their delta index, six after Thalidomide failed the attention test and showed an increase in the delta index greater than that found in any control.

If it is accepted that patients with severe encephalopathy are liable to deteriorate as a result of operation, it is felt that this study shows that patients with a lesser degree of pre-operative encephalopathy, as shown by careful E.E.G. assessment, are more liable to show some post-operative deterioration than those whose E.E.G. findings are within normal limits. It should be emphasized that the assessment of the effect of operation was made after only seven days and that in only two cases did the post-operative confusion persist. It is obvious that the selection of patients for operation is a clinical problem and must be based on the consideration of a variety of factors. Results published from the department in which the present investigation was carried out (Gillingham et al., 1960), which made no mention of E.E.G. criteria for selection, were very good. Nonetheless, we agree with those authors (England et al., 1959; Hassler et al., 1960), who feel that pre-operative E.E.G. assessment may be of value. Furthermore, although relatively gross abnormalities may be seen on a single routine record, we feel that the demonstration of an abnor $z$ mal E.E.G. response to a sedative-hypnotic type of drug may demonstrate a slight degree of encephalow pathy. Although such a demonstration would nots necessarily contraindicate operation, it might be of help in a borderline case in deciding whether or not to operate, or how large a lesion to make.

\section{SUMMARY}

The E.E.G. recordings with frequency analysis and $\frac{\overrightarrow{\vec{f}}}{a_{0}^{4}}$ simple test of attention were carried out before and after Thalidomide ( $1 \mathrm{mg}$. $/ \mathrm{kg}$. body weight) had been given to 20 controls and 20 to Parkinson patients before and after stereotactic operations.

Constrasted with the control group the Parkinsonis group showed a significantly lower mean frequency $\overrightarrow{0}$ and higher delta index for their baseline records and a significantly greater fall in mean frequency, rise inc delta index, and more failures in the attention test after Thalidomide.

The pre-operative E.E.G. findings of the Parkinsom group are considered in relation to the effects $\theta$ f operation on the E.E.G. and the test of attention.

The value of the E.E.G. in helping to select patients for operation is considered.

We would like to thank Professor F. John Gillinghăm Mr. P. Harris, and Mr. J. Shaw for the opportunitydo study patients under their care and Dr. A. S. Brown his advice.

\section{REFERENCES}

England, A. C., Schwab, R. S., and Peterson, E. (1959). The electro encephalogram in Parkinson's syndrome. Electroenceph. clin Neurophysiol., 11, 723-731.

Gillingham, F. J., Watson, W. S., Donaldson, A. A., and Naughton? J. A. L. (1960). The surgical treatment of Parkinsonism. Brit med. J., 2, 1395-1402

Hassler, R., Riechert, T., Mundinger, F., Umbach, W., and Gangl berger, J. A. (1960). Physiological observations in stereotaxif operations in extrapyramidal motor disturbances. Brain, 83, 337-350.

Laidlaw, J., and Read, A. E. (1961). The electroencephalographie diagnosis of manifest and latent 'delirium' with particular reference to the complicating hepatic cirrhosis. $J$. Neurol Neurosurg. Psychiat., 24, 58-70.

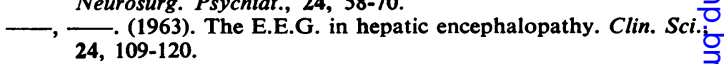

Mensiková, Z., Nádvornik, P., and Petr, R. (1963). The electro encephalogram of Parkinson's syndrome in relation to stereo? tactic thalamotomy. Electroenceph. clin. Neurophysiol., 15, 168윽

Sirakov, A. A., and Mezan, I. S. (1963). EEG. findings in Parkinson ism. Ibid., 15, 321-322. 